\title{
PRAZO RAZOÁVEL DO PROCESSO: LIBERDADE DE IMPRENSA VERSUS PRESUNÇÃO DE INOCÊNCIA DO ACUSADO
}

\author{
Tiago Oliveira de Castilhos* \\ Valdir Florisbal Jung ${ }^{* *}$
}

\begin{abstract}
RESUMO
O artigo propõe a reflexão sobre o princípio da razoável duração do processo, análise da influência ou não da imprensa no trâmite dos processos de crimes de maior repercussão. A liberdade de expressão da mídia prevalece sobre a presunção de inocência nesta sociedade acuada pela (in)segurança pública? $O$ que a torna mais propensa a confundir justiça e a vingança? Para aprofundar o tema a análise será feita comparativamente entre dois processos de homicídio que tramitaram em Canoas. Ambos tiveram autorias identificadas, mas um ganhou ampla cobertura midiática e celeridade.
\end{abstract}

Palavras-chaves: Duração do Processo; Prazo Razoável do Processo; Homicídio; Tribunal do Júri; Imprensa.

\section{REASONABLE PERIOD OF PROCEEDINGS: FREEDOM OF THE PRESS VERSUS PRESUMPTION OF INNOCENCE OF THE ACCUSED}

\begin{abstract}
The article proposes to reflect on the principle of the reasonable length of the process, analysis of the influence or not of the press in the process of the processes of crimes of greater repercussion. Does the freedom of expression of the media prevail over the presumption of innocence in this society that is undermined by (in) public safety? What makes you more likely to confuse justice and revenge? To deepen the subject the analysis will be made comparatively between two homicide proceedings that processed in Canoas. Both had identified authorships, but one gained wide media coverage and speed.
\end{abstract}

Key Words: Duration of the Process; Reasonable time of the Process; Murder; Jury court; Press.

\section{Introdução}

\footnotetext{
*Advogado. Doutorando em Ciências Criminais PUC/RS. Mestre em Ciências Criminais PUC/RS. Especialista em Ciências Penais PUC/RS. Bacharela em Direito UniRitter. Professor da Escola de Formação Jurídica da FADERGS e Professor convidado da Pós-Graduação, Latu Sensu, da UniRitter. Contato e-mail: tiago.castilhos@fadergs.edu.br ** Advogado. Mestrando em Direitos Humanos pela UniRitter. Especialista em Direito Penal e Processo Penal pela Ulbra. Especialista em Docência do Ensino Superior pelo Centro Universitário Leonardo da Vinci - IERGS. Bacharel em Direito Ulbra. Professor convidado da Pós-Graduação, Latu Sensu, da UniRitter.Contato e-mail: valdirjung.adv@gmail.com
}

Revista de Direito Penal, Processo Penal e Constituição | e-ISSN: 2526-0200 | Goiânia | v. 5 | n. 1 | p. 22 - 41 | Jan/Jun. 2019. 
Entre os princípios fundamentais que norteiam o processo penal brasileiro está a garantia da razoável duração do processo, inserido no rol do art $5^{\circ}$ da Constituição Federal, por meio da Emenda Constitucional $n^{\circ} 45$, de 30 de dezembro de 2004. De acordo com o inciso LXXVIII, é assegurado a todos, no âmbito judicial e administrativo, a razoável duração do processo e os meios que garantam a celeridade de sua tramitação..$^{\dagger}$

Introduzido no ordenamento jurídico esse instituto de Direitos Humanos, ${ }^{*}$ com status de princípio fundamental, pois a ideia de estabelecer um prazo razoável tem o intuito de conceder maior celeridade à prestação jurisdicional e evitar demora do Estado na prestação jurisdicional. Nesse caso, deve-se buscar um equilíbrio, respeitando os princípios da razoabilidade e da proporcionalidade, para que o processo não se estenda além do razoável, mas também não comprometa o direito a plena defesa e o contraditório. Tanto uma prestação jurisdicional apressada quanto o excesso de tempo para a conclusão de um processo podem resultar em injustiça ou em sensação de injustiça, sensação de que o Estado não tem interesse em apurar os ilícitos praticados em seu interior.

Na prática, porém, a duração razoável do processo se apresenta como um conceito vago, que depende, entre outros fatores, de um sistema judicial eficaz, dotado de todo o aparato e estrutura necessária, além da verificação de alguns requisitos estabelecidos por este mesmo poder judiciário a de identifica o excesso. No âmbito criminal, área de estudo do presente artigo, o tempo excessivo dos processos motiva uma série de críticas ao Judiciário e contribui para o sentimento de impunidade pela sociedade brasileira.

Os profissionais que atuam na área do direito criminal se deparam, com frequência, com a aplicação da prisão preventiva que, ao contrário da prisão temporária (Lei 7.960/89), cuja duração é de 5 (cinco) dias, prorrogáveis por igual período - exceto nos casos de crimes hediondos, nos quais se aplicam 30 (trinta) dias prorrogáveis por mais 30 (Lei 8.072/90), não possui prazo legal pré-estabelecido.

\footnotetext{
†BRASIL. Constituição Federal (1988). Art 5', inciso LXXVIII - "a todos, no âmbito judicial e administrativo, são assegurados a razoável duração do processo e os meios que garantam a celeridade de sua tramitação." (Incluído pela Emenda Constitucional no 45 , de 2014)

* O artigo $8^{\circ}$ do Pacto de San Jose da Costa Rica, de 1969, internalizado e ratificado pelo Brasil pelo Decreto $\mathrm{n}$. 6788/1992 e com sua adesão em 25/9/1992, que versa que as garantias judiciais, entre elas a de que a pessoa que está sendo acusada pelo Estado deve ser ouvida dentro de um prazo razoável por um juiz competente. Informações colhidas no sitio da Comissão Interamericana de Direitos Humanos. Disponível em: < https://www.cidh.oas.org/basicos/portugues/d.Convencao_Americana_Ratif..htm > Acesso em: 10 fev. 2019.
}

Revista de Direito Penal, Processo Penal e Constituição | e-ISSN: 2526-0200 | Goiânia | v. 5 | n. 1 | p. 22 - 41 | Jan/Jun. 2019. 
Ao não definir um tempo razoável de duração para a prisão preventiva e medidas cautelares, o legislador deixou essa responsabilidade a cargo do juiz, cujas decisões podem ser tomadas com base em diferentes critérios, objetivos e subjetivos, sendo os critérios subjetivos a grande problemática sobre a caracterização do excesso de prazo na aplicação da medida (deve-se perceber que o olhar sobre a aplicação da prisão preventiva ou sobre as medidas alternativas a prisão deve ser situacional, ou seja, as medidas servem para impor/parar/estancar uma situação. Logo, assim que cessada a situação deve cessar também a medida ou a prisão).

O presente artigo busca analisar, de forma crítica, a influência da mídia nos processos que envolvem crimes de grande repercussão popular no que se refere aos excesso de prazo de duração ou de aceleração de um processo criminal. Nesses casos, não são raras as vezes em que o papel da imprensa ultrapassa o direito à informação, ficando claro o conflito entre dois direitos fundamentais: a liberdade de expressão e a presunção de inocência do acusado ou os interesses pelos quais atua publicizando mais sobre um caso do que outro, fazendo assim a aceleração do processo que é o objeto de seu(s) interesse(s).

Para o desenvolvimento do tema, o trabalho apresenta como ponto de partida a análise do princípio razoável duração do processo e a concepção de tempo. Em seguida, revive casos emblemáticos em que a cobertura dada pela imprensa condenou os suspeitos e acelerou o processo, antes mesmo de serem acusados oficialmente e irem a julgamento. Após, o texto traça um paralelo entre o tratamento dado a dois processos em tramitação na Comarca de Canoas, no Estado do Rio Grande do Sul - RS, município da região metropolitana de Porto Alegre, tendo um deles ganhado ampla repercussão na imprensa.

\section{Prazo razoável do processo}

O Poder Judiciário brasileiro finalizou o ano de 2017 com 80,1 milhões de processos em tramitação, aguardando alguma solução definitiva, de acordo com o relatório Justiça em Números, do Conselho Nacional de Justiça. ${ }^{\S}$ Desses, 14,5 milhões (18,1\%) estavam

\footnotetext{
${ }^{\S}$ BRASIL. Conselho Nacional de Justiça. Justiça em Números 2018. Brasília, 2018.Disponível em<http://www.cnj.jus.br/files/conteudo/arquivo/2018/08/44b7368ec6f888b383f6c3de40c32167.pdf>. Acesso em: 04 fev. 2019
}

Revista de Direito Penal, Processo Penal e Constituição | e-ISSN: 2526-0200 | Goiânia | v. 5 |

n. 1 | p. 22 - 41 | Jan/Jun. 2019. 
suspensos, sobrestados ou em arquivo provisório, aguardando alguma situação jurídica futura. Ainda, segundo o documento, em toda série histórica, o ano de 2017 foi o de menor crescimento do estoque, com variação de $0,3 \%$, o que representou um incremento de 244 mil casos em relação ao saldo de 2016.

Apesar de decidir 6,5\% de casos acima da demanda, o que deveria resultar em uma redução do estoque nessa proporção, isso não ocorreu. Um dos fatores está relacionado aos processos que retornam à tramitação, como, por exemplo, os casos de sentenças anuladas na instância superior e de remessas e retornos de autos entre tribunais em razão de questões relativas à competência ou de mudança de classe processual. Houve a reativação de 619.242 processos em 2017.

Abaixo, os gráficos contribuirão com a análise referida, sendo o primeiro sobre a oscilação visível entre os anos e números de casos novos e casos baixados, podendo visualizar-se que não há grande diferença entre eles. Já o segundo gráfico contribui para a análise dos casos pendentes, em comparação com os processos suspensos e reativados sendo visível que ou os registros iniciaram em um tempo recente ou a prática iniciou-se recentemente, no que se refere a suspensão de processos e a reativação deles.

\section{Série histórica dos casos novos e processos baixados}

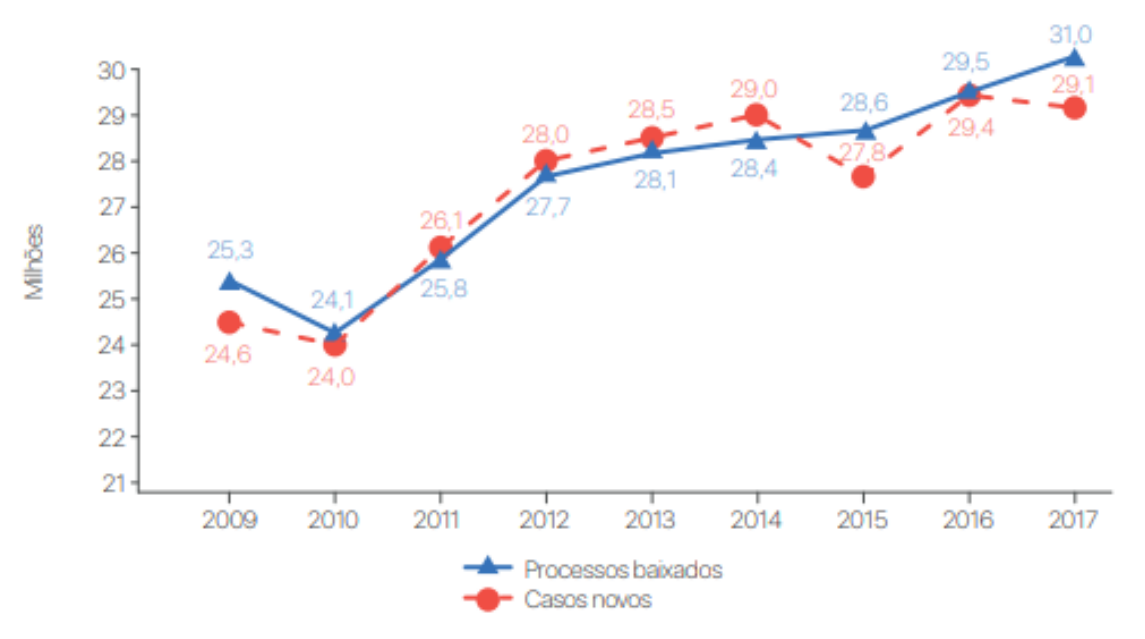

Revista de Direito Penal, Processo Penal e Constituição | e-ISSN: 2526-0200 | Goiânia | v. 5 |

n. 1 | p. 22 - 41 | Jan/Jun. 2019. 


\section{Série histórica dos casos pendentes}

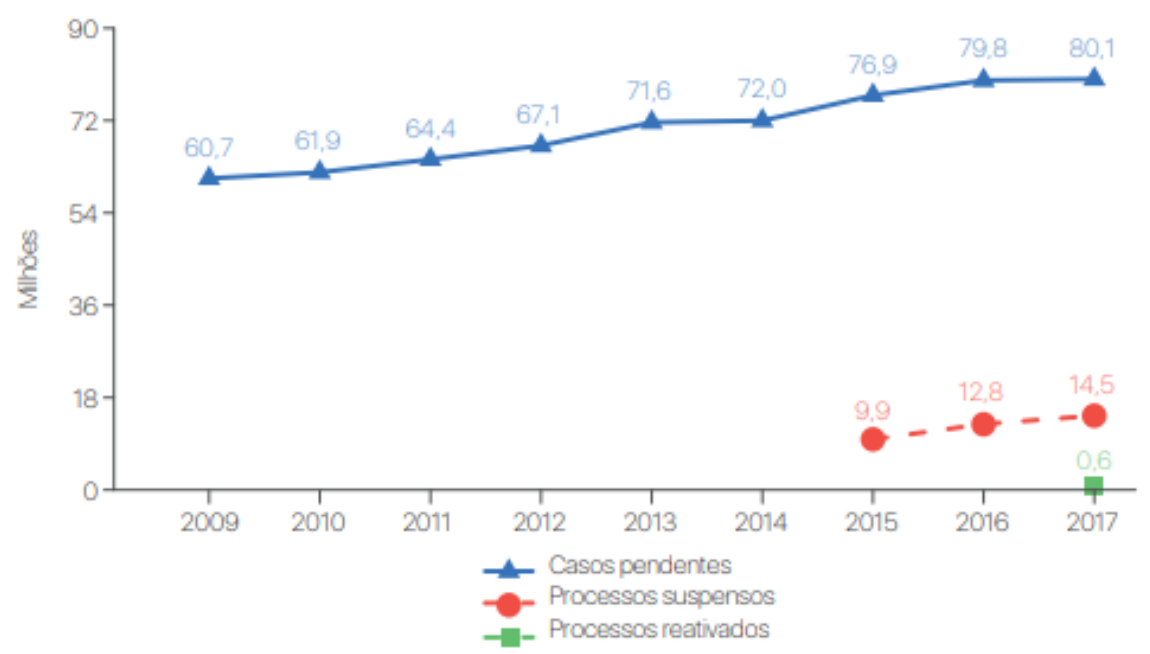

Fonte e Arte: CNJ

Os números permitem ilustrar a situação do Judiciário brasileiro e ajudam a compreender porque existe, em diferentes setores, a imagem de um sistema moroso que não consegue atender as demandas da sociedade com a celeridade necessária. O processo envolve uma série de ritos e procedimentos, portanto não se pode esperar um provimento imediato. Por outro lado, não pode extrapolar o limite da duração razoável que é um direito humanitário presente no Pacto de San Jose da Costa Rica.

Embora o processo não seja um instrumento apto a fornecer uma resposta imediata àqueles que dele se valem, isto não pode levar ao extremo oposto de permitir que tal resposta seja dada a qualquer momento. Se o processo demanda tempo para a sua realização, não dispõe o órgão julgador de um tempo ilimitado para fornecer a resposta pleiteada. (LOPES JR e BADARÓ, 2009, p. 6) 
Ultrapassar o limite da duração razoável de um processo, especificamente do processo penal, pode ter efeitos irreversíveis, pois o Estado se apossa ilegalmente do tempo do particular (LOPES JR e BADARÓ, 2009, p. 6). Para MESSUTI, não é apenas a separação física que define a prisão, pois os muros não marcam somente a ruptura no espaço, mas também a ruptura do tempo e do espaço (MESSUTI, 2003, p. 17). ${ }^{* *}$ Os danos por uma prisão apressada e injusta são irreparáveis. "Existe uma grande diferença entre passar três dias na prisão e passar toda a vida: há toda uma vida de diferença” (MESSUTI, 2003, p. 33).

Um processo que leva muito tempo para ser julgado, pode levar à prescrição, ao acúmulo de processos, perda de provas, tanto para condenar como para absolver e gera uma sensação de impunidade e de descaso com a sociedade. Quando o processo penal se estende de forma indevida ocorre a violação de uma série de direitos humanos dentre eles o direito de ser julgado em um prazo razoável.

Pune-se através de quantidade de tempo e permite-se que o tempo substitua a pena. No primeiro caso, é o tempo do castigo, no segundo, o tempo do perdão e da prescrição. (LOPES JR e BADARÓ, 2009, p. 9).

Com razão os autores pois a punição vem com o aprisionamento com o foco não mais no corpo do condenado, mas sim sobre o tempo dele. Sabe-se que se vive uma "telepresença" nas palavras de VIRILIO (VIRILIO, 1993, p. 13), hoje e por conta dela o tempo e espaço são sentidos de forma diferente, com sensação de uma aceleração nunca antes vista. Ainda, as redes sociais provenientes destas novas tecnologias que estabelecem novas relações e acesso a informação em tempo real. Essa "telepresença" apresenta-se em uma sociedade que está em crise (POZZEBON, 2005, p. 12),,$^{\dagger \dagger}$ globalizada, das novas tecnologia (THUMS, 2003, p. 3), ${ }^{\dagger}$ do imediato a ponto de ser ao tempo do clique do botão "enter" o que verdadeiramente importa, do prazer, do descartável, do fugaz, não sendo mais crível a

\footnotetext{
** Explica a autora que para o Direito Penal "[...], o tempo é a medida de uma pena que se converteu praticamente na pena por excelência: [...]", ou seja, a demora do processo também é pena para além do tempo de prisão. O tempo, para autora, é o verdadeiro significante da pena, logo a punição se dá também pelo transcurso do tempo, logo, da demora também se dá a punição. No que se refere ao espaço a punição se dá pela estaticidade do lugar da prisão.

${ }^{\dagger}$ A crise do conhecimento moderno diz respeito a uma fragilização da aplicação dos institutos do direito e no caso do tempo uma maior fragilização destes institutos, pois a percepção hoje é diferente do passado. Logo, surge uma necessária valorização de direitos e garantias justamente para proteger o indivíduo, pois a percepção é outra.

\# Explica o autor que a tecnologia, a evolução, propiciou desenvolvimento antes não visto, como, por exemplo, o tempo das comunicações no exato momento do acontecimento em tempo real, ou seja, a velocidade das informações por conta das novas tecnologias dão outra percepção de tempo.
} 
aceitação de uma concepção como essa proposta pelos juristas no processo, ou seja de um tempo do relógio, um tempo estático, da fixidez (HAWKING, 2015, p. 17) ${ }^{\S \S}$ do tempo, de uma leitura linear, um tempo de que pouco importa quanto leve o processo ou a prisão, pois ele é apenas "tempo" (MORETTO, 2005, p. 31), ${ }^{* * *}$ cheio de dor, incerteza e sofrimento.

O tempo não é mais sentido da mesma forma em que pese ser computado da mesma forma, pois ainda registramos o tempo no relógio, mas o sentimento que este tempo passa é outro totalmente diferente, hoje, do que era após a $2^{\mathrm{a}}$ Guerra Mundial.

Por conta desta sensação de aceleração, por conta desta sensação de rapidez fugaz é que surge como direito humano aquele que trata da razoável duração do processo, pois independentemente de ter prisão antes do trânsito em julgado ele serve, o processo, como pena (MESSUTI, 2003, p. 17), pois há sofrimento da espera tanto da vítima quando daquele que está sendo acusado do cometimento de uma crime, pois não sabe o seu futuro, sendo ele incerto.

Com a teoria da relatividade surge esta ideia de mudança na percepção de tempo, tratando-se de sentir o tempo de forma diferente com a subjetividade presente, pois deixou ele de ser absoluto. Einstein de forma magistral explica a sua empregada sobre a teoria da relatividade, pois ela tem curiosidade já que o mestre tanto estuda a relatividade (HAWKING, 2002, p. 21)..$^{\dagger \dagger}$

Ele, explica a ela, de forma bem sucinta e rápida o que seria a teoria da relatividade por meio do exemplo do namoro no portão e da chapa quente do fogão. Pergunta ele a ela: quando namoras no portão, no seu horário de intervalo, que sensação tens? o tempo passa morosamente ou de forma rápida? Ela responde: de forma rápida ao ponto de nem vê-lo passar. A seguir diz ela para ela: sente agora na chapa do fogão que está muito quente, que sensação terá? Que um segundo na chapa parece uma eternidade. Logo, o tempo no portão que foi de hora aparentava para a emprega ser um tempo tão rápido e o tempo sentado na chapa do fogão, tempo de um segundo, pareceu a eternidade. Explica assim Einstein a sua

\footnotetext{
$\S \S$ É impossível ter um modelo estático, ou seja, o tempo não é estático, não é fixo como se propõe o processo penal.

Explica que "Com a física do século XX, temos uma nova visão do mundo. O espaço-tempo, que fazia parte da imagem de nosso universo, perdeu seu poder para a luz-velocidade".

${ }^{\dagger \dagger}$ Eistein propôs um modelo matemático que refutava o modelo newtoniano vigente. Surge, então, em 1915, a Teoria Geral da Relatividade. Ideia de tempo subjetivo.
} 
empregada a teoria da relatividade que rompe com a ideia de tempo absoluto (HAWKING, 2015, p. 34-35).

Para o jurista o tempo computado no processo é um tempo vinculado ao absoluto, ao computo do tempo do relógio (LOPES JR., 2006, p. 96), senhor de tudo, deixando de lado a subjetividade inerente ao sentimento e a aceleração proveniente das novas tecnologias e da velocidade ao qual chega a informação ao nosso conhecimento e ela traz uma nova percepção de tempo que é relativa, pois uma hora do relógio é mais produtiva, por conta da aceleração, do que era na metade do século passado. Para GAUER o tempo tem um complicador.

[...] Se o home ocidental contemporâneo transformou-se em uma caricatura de si próprio, pelo seu modo de ser cada vez mais agressivo, segundo alguns analistas, venerou, por outro lado, mesclas de 'realidades' e, consequentemente, de necessidades sociais. Tal processo é análogo ao vivido pelo homem do século passado, ressalvando-se uma diferença: o tempo, hoje, mescla evidências portadoras de um complicador sumariamente problemático, isto é, a velocidade que elimina os intervalos de tempo (GAUER, 2016, p. 39).

No que se refere ao processo penal, no Brasil, o computo do tempo de pena e do tempo de processo deve receber ainda a carga de toda a mazela (GAUER, 2016, p. 39) inerente ao próprio sistema o que causa uma sensação inversa do sentimento em sociedade, pois na prisão, com o quadro que se encontram as prisões brasileiras, a sensação é de uma eternidade. No caso do exemplo de Einstein, seria a sensação de sentar na chapa e ficar até fritar, ou seja, uma eternidade.

Tanto o legislador quando o juiz não se preocupam com o tempo de espera/demora do processo a não ser para fundamentar o discurso que a demora é causada pela defesa e por consequência é a causadora da impunidade, sendo esse um dos motivos, hoje, da decretação da prisão preventiva em situações que ela nunca seria aplicada [regime fechado - por que este é o regime da prisão preventiva] se condenado fosse de forma sumária o acusado [lembre-se que o regime fechado só é determinado para penas a cima de 8 (oito) anos, na forma do Art. 33, $2^{\circ}$, alínea "a", do Código penal - CP]. Ou seja, aplica-se a prisão preventiva em casos em que a pessoa nunca iria para o regime fechado, quando do momento da condenação, por que o

\footnotetext{
" A problemática está "[...] no sentido da percepção. [...]." Ou seja, na percepção que cada indivíduo tem de tempo e aqui, especificamente, tempo de sofrimento.
}

Revista de Direito Penal, Processo Penal e Constituição | e-ISSN: 2526-0200 | Goiânia | v. 5 | 
crime imputado não lhe permite, pois a condenação nunca alcançaria os 8 (oito) anos de prisão.

A nova percepção de tempo não chega ao processo com o intuito de garantir a elucidação do caso penal com qualidade, garantias processuais e ao mesmo momento celeridade necessária. Chega a reclamação de tempo, de demora, com olhar na acusação, no discurso da impunidade e com a necessidade dos adeptos deste discurso de rever o tempo do processo, pois a impunidade é grande e o manejo da defesa para que o processo penal demore também é grande. Percepções equivocadas e direcionadas a satisfação de uma ideologia recrudescedora.

Esse tipo de informação, qual seja, a de que o processo demora por causa da defesa ou por causa dos recursos manejados por ela nada mais são do que Fake News (D'ANCONA, 2018 , p. 25$),{ }^{\S \S}$ com detalhe, pois o termo é novo, mas a prática antiga.

A pergunta a tentar responder é: qual o prazo razoável no processo penal. A sugestão doutrinária seria a de olhar para os nossos visinhos, como, por exemplo, o Paraguai, que fez uma reforma em seu processo penal e usar como modelo. Ou seja, a razoável duração do processo seria a de 3 (três) anos sendo prorrogável por mais 6 (seis) meses caso, sendo justificado, caso não consiga resolver o problema penal (CASTILHOS, 2013, p. 140).

Artigo 136. DURAÇÃO MÁXIMA. Toda pessoa terá direito a uma solução judicial definitiva em um prazo razoável. Portanto, todo procedimento terá uma duração máxima de três anos, contados desde o seu primeiro ato. ${ }^{* * * *}$

O tema é complexo e encontrará uma série de senão, de desculpas, dentre tantas aquela que diz que no Brasil não funcionaria por que ele é continental, tudo é mais demorado, grande extensão territorial, tudo para não fazer qualquer mudança e para não tentar como fizeram os vizinhos paraguaios.

\footnotetext{
$\$ \S \S$ Os fatos verdadeiros não importam, mas sim o impacto que estes fatos narrados podem causar: "O que importa não é a veracidade, mas o impacto. [...]." Conforme Trump o que importa é a história e não os fatos!

***** O texto está disponível em: < http://www.oas.org/juridico/mla/pt/pry/index.html >. Acesso em: 10 fev. 2019. "Artículo 136. Toda persona tendrá derecho a una resolución judicial definitiva en un plazo razonable. Por lo tanto, todo procedimiento tendrá una duración máxima de tres años, contados desde el primer acto del procedimiento303. Este plazo sólo se podrá extender por seis meses más cuando exista una sentencia condenatoria, a fin de permitir la tramitación de los recursos." Exposto na citação por tradução livre dos autores.
}

Revista de Direito Penal, Processo Penal e Constituição | e-ISSN: 2526-0200 | Goiânia | v. 5 | 
A discussão mais aprofundada pode ser travada em outro momento, quando poderia buscar mais elementos de pesquisa e mais fôlego.

\section{A mídia e os casos de maior repercussão popular}

No Brasil, a liberdade de expressão é um direito fundamental e, assim sendo, o seu exercício está associado diretamente aos conceitos de democracia e cidadania. O inciso IX do art. $5^{\circ}$ da Constituição Federal estabelece: "é livre a expressão da atividade intelectual, artística, científica e de comunicação, independentemente de censura ou licença”. A Carta Magna traz ainda no art. 220: "A manifestação do pensamento, a criação, a expressão e a informação, sob qualquer forma, processo ou veículo, não sofrerão qualquer restrição". De acordo com o $\S 1^{\circ}$ e $2^{\circ}$ do mesmo artigo, nenhuma lei poderá conter dispositivo de cerceamento da plena liberdade de informação jornalística em qualquer veículo de comunicação social, sendo vedada toda e qualquer censura de natureza política, ideológica e artística.

A redemocratização, no final da década de 1980, devolveu aos brasileiros o direito fundamental da livre manifestação de pensamento. Concomitantemente à liberdade de expressão, retomou-se, após 20 anos de ditadura militar, a liberdade de imprensa no país. Eficaz instrumento do sistema democrático, a liberdade de imprensa permite, por exemplo, conter abusos cometidos por autoridades públicas, mostrando-se uma ferramenta fundamental para dar transparência aos atos dos governos, seja em âmbito nacional, estadual ou municipal.

Espera-se do jornalista imparcialidade na cobertura dos fatos, embora seja praticamente impossível alcançar $100 \%$ de isenção, uma vez que ele carrega consigo uma bagagem cultural, vivências e opiniões. Além disso, os veículos de comunicação são regidos por linhas editoriais, influenciadas, entre outros aspectos, por questões comerciais.

No momento de informar sobre determinado fato, a imprensa deve dar espaço para o contraponto, possibilitando, assim, que o expectador formule sua própria opinião sobre o fato. Na prática, porém, percebe-se que o papel da imprensa ganhou, ao longo da história, novos contornos, que a transformaram em formadora de opinião, capaz de eleger ou depor governantes.

Revista de Direito Penal, Processo Penal e Constituição | e-ISSN: 2526-0200 | Goiânia | v. 5 | n. 1 | p. 22 - 41 | Jan/Jun. 2019. 
Rui Barbosa afirmavaque a "imprensa é a vista da Nação" e chamava a atenção para a sua necessidade e o risco de sua falta.

Por ela é que a Nação acompanha o que lhe passa ao perto e ao longe, enxerga o que lhe malfazem, devassa o que lhe ocultam e tramam, colhe o que lhe sonegam, ou roubam, percebe onde lhe alveja, ou nodoam, mede o que lhe cerceiam, ou destroem, vela pelo que lhe interessa, e se acautela do que a ameaça. (BARBOSA, 1990, p. 20-22)

Um país de imprensa degenerada ou degenerescente é, portanto, um país cego e um país miasmado, um país de idéias falsas e sentimentos pervertidos, um país, que, explorado na sua consciência, não poderá lutar com os vícios, que lhe exploram as instituições. (BARBOSA, 1990, p. 2022)

Na cobertura policial, especialmente, percebe-se a predominância da fonte oficial. É como se a versão apresentada pelo Estado fosse automaticamente aceita e ganhasse status de verdade, com a destinação de um espaço mínimo para os argumentos da defesa - quando é concedido algum espaço. O próprio Código de Ética dos jornalistas estabelece, entre seus preceitos, que um dos fundamentos da atividade jornalística é a presunção da inocência. É proibida também a divulgação de informações de caráter sensacionalista, especialmente em cobertura de crimes e acidentes. ${ }^{\dagger \dagger \dagger \dagger}$

Não há como negar que a espetacularização da tragédia dá ibope e esse tem sido um recurso utilizado pelas empresas de comunicação para prender a atenção dos leitores, ouvintes ou telespectadores. As manchetes sensacionalistas estão também nos portais de notícia na Internet, como forma de obter cada vez mais visualizações.

Sensacionalismo é tornar sensacional um fato jornalístico que, em outras circunstâncias editoriais, não mereceria esse tratamento. Como o adjetivo indica, trata-se de sensacionalizar aquilo que não é necessariamente sensacional, utilizando-se para isso de um tom escandaloso, espalhafatoso. Sensacionalismo é a produção de noticiário que extrapola o real, que superdimensiona o fato. Em casos mais específicos, inexiste a relação com qualquer fato e a "notícia" é elaborada como mero exercício ficcional. (ANGRIMANI, 1995, p. 16) †it Código de Ética dos Jornalistas Brasileiros. Disponível em: <https://fenaj.org.br/wp-
content/uploads/2014/06/04-codigo_de_etica_dos_jornalistas_brasileiros.pdf>. Acesso em: 06 fev.2019

Revista de Direito Penal, Processo Penal e Constituição | e-ISSN: 2526-0200 | Goiânia | v. 5 |

n. 1 | p. 22 - 41 | Jan/Jun. 2019. 
O sensacionalismo faz parte de uma cultura instalada de comercialização da desgraça da vítima e do algoz ao mesmo tempo e isso afeta tanto a vida da vítima quanto daquele que está sendo acusado de ter cometido um crime, muitas vezes podendo ser crucial para a sua condenação, como, por exemplo, nos próprios casos que vão ao Tribunal do Júri que o Conselho de Sentença faz parte da comunidade e tem aceso a essas informações.

No próximo subtítulo tratar-se-á dos casos emblemáticos e que foram propagados na mídia de forma sensacionalista com resultados nefastos.

\subsection{Casos emblemáticos}

A imprensa teve papel crucial na condenação prévia e, até mesmo, judicial de acusados, como, por exemplo, o caso da Escola de Educação Infantil Base, em São Paulo (SP), tornou-se um dos mais conhecidos símbolos da atuação equivocada da imprensa. Em 1994, os donos da escola infantil,o responsável pelo transporte escolar e os pais de um dos alunos foram acusados de abusar sexualmente de crianças de 4 anos de idade, após denúncia feita por duas mães.

Os principais veículos de comunicação do país passaram a dar destaque ao caso, com base nas afirmações feitas pelo delegado e pelos pais das supostas vítimas. Sem provas o inquérito policial foi arquivado, mas os envolvidos já tinham sido julgados não pela Justiça, mas sim pela opinião pública. Nesse meio tem a a escola já havia sido fechada, depredada e a vida dos acusados sofrido prejuízos irreparáveis.

Outro erro clássico da interferência da imprensa é o crime do Bar Bodega (DORNELES, 2007), que ocorreu em 1996. Nove jovens foram detidos e acusados de terem assassinado o dentista José Renato Tahan e a estudante de Odontologia Adriana Ciola, durante um assalto no estabelecimento que dá nome ao caso, localizado em um bairro nobre (Moema) de São Paulo. Na contramão da campanha feita pelos veículos de comunicação contra os acusados, destacou-se a atuação do promotor Eduardo Araújo da Silva que desconfiado da acusação da polícia contra os presos (incongruentes, pois detalhes físicos e etários dos acusados não fechavam), trabalhou para mudar os rumos da investigação, conseguindo a liberdade dos mesmos. Constatou-se à época que as confissões haviam sido obtidas por meio de tortura.

Revista de Direito Penal, Processo Penal e Constituição | e-ISSN: 2526-0200 | Goiânia | v. 5 | n. 1 | p. 22 - 41 | Jan/Jun. 2019. 
O caso do Bar Bodega demonstra ainda o quanto as investigações e processos podem ser acelerados em virtude da cobrança da imprensa por uma resposta rápida e os riscos que isso pode representar. Não há como negar, no entanto, que quando age com responsabilidade a imprensa dá a sua contribuição para que os crimes não corram o risco de cair no esquecimento.

Observa-se que um processo que está sendo acompanhado pela mídia tem a sua conclusão e seus prazos acelerados, o que, muitas vezes, pode levar à violação dos Direitos Humanos.

Em abril de 1995, um atentado em Oklahoma City fez sessenta e oito mortos e deixou a América chocada. Enquanto as autoridades mal começavam a fazer a investigação, a mídia, ávida por satisfazer a opinião pública, exigia culpados e conseguiu que responsáveis pela administração, quarenta e oito horas depois, apontassem com o dedo o "terrorismo do Oriente Próximo" e que " suspeitos" de origem árabe fossem rapidamente detidos. Entretanto, os verdadeiros autores do atentado, descobertos alguns dias, eram americanos brancos, ligados à extrema-direita, em rebelião contra o Estado federal. (RAMONET, 2010, p. 72).

Espera-se do julgador que as suas deliberações sejam norteadas pelo debate racional, que ele não permita que as emoções interfiram no processo de tomada de decisão o que se sabe ser utópico, pois razão e emoção andam juntas [não existe um botão que o juiz possa se desprender da emoção e julgar com a razão apenas]. Essa leitura é cartesiana, pois razão dissociada da emoção é uma forma de pensar cartesiana e por consequência superada, ou deveria já ser superada.

Decarte abre a sua obra falando sobre um "bom senso" e um "bem julgar", no primeiro diz que todos estão a pensar que bem provido estão dele, já o segundo é parte integrante do primeiro, pois é com base no "bom sendo" que se da o "bem julgar" que é propriamente a razão, sendo que para o autor a razão é igual em todos os homens sendo diferente as opiniões ocorrem por que se conduz o pensamento por vias diferentes e não por que uns são mais racionais do que os outros (DESCARTES, 2009, p. 37).

Assim se estabeleceu o método de pensamento que abre a modernidade e que serve de fio condutor para a ciência.

\footnotetext{
$\$ \$$ Os ponto de vista se da diferente por que se considera as coisas do mundo de forma diferente e por conta disso o pensamento é diferente, mas não por que somos mais racionais do que as outras pessoas.
} 
Mas o que mais contentava nesse método é que por ele eu tinha a certeza de usar em tudo minha razão, se não perfeitamente, ao menos da melhor maneira possível: além disso eu sentia, praticando-o , que meu espírito se acostumava aos poucos a conceber mais claramente e mais distintamente seus objetos, e me prometia, não o tendo submetido a nenhuma matéria particular, aplicá-lo de maneira igualmente útil às dificuldades das outras ciências, como fizeram com as da álgebra (DESCARTES, 2009, p. $58)$.

Fica claro que o autor trata de uma método de pensamento, um método para pensar as coisas do mundo aplicando para as demais ciências. É necessário, para usar a metáfora do próprio autor, derrubar a casa e reconstruí-la, mas para isso o autor cria uma moral própria que também é calcada em um método. Todo o pensamento passa por um método e ele deve levá-lo a conhecer a verdade (DESCARTES, 2009, p. 59-63).

Disso tudo extrai a máxima "penso, logo existo", sendo uma verdade e que ela não pode ser abalada por qualquer outro pensamento nem a dos mais céticos (DESCARTES, 2009, p. 70)..$^{\S \S \S}$ Tudo passa pelo pensamento, pela reflexão, pois nada passa nem aos olhos, nem aos outros sentidos se não pelo exercício do pensamento (DESCARTES, 2009, p. 75) e nele está o método para o conhecimento, só se conhece alguma coisa por meio do método e ele decorre do pensamento e da reflexão.

Então ocorre o império do pensamento reflexivo em busca da verdade por meio de um método, sendo aplicado a toda forma de pensamento e a todas as ciências, tendo como máxima o "penso, logo existo". Um ganho muito grande se estabeleceu por conta desta forma de pensar, desta forma de concatenar o pensamento o que norteou as ciências moderna.

No entanto, ao longo do tempo este pensamento puramente racional foi questionado, pois pensar racionalmente não pode estar afastado dos sentimentos.

Sugeri no início do livro que os sentimentos exercem uma forte influência sobre a razão, que os sistemas cerebrais necessários aos primeiros se encontram enredados nos sistemas necessários à segunda e que esses sistemas específicos estão interligados com os que regulam o corpo (DAMÁSIO, 2012, p. 216).

\footnotetext{
$\$ \S \S$ Compreendeu o autor que ele era uma ser, um essência que tinha a natureza de pensar, não sendo refutável isso.
}

Revista de Direito Penal, Processo Penal e Constituição | e-ISSN: 2526-0200 | Goiânia | v. 5 | 
A razão não está a par dos sentimentos, pois a razão depende de sistemas cerebrais específicos e estes sistemas acabam por processar também os sentimentos. Constata então que para a razão ser processada depende ela de uma base biológica e consequentemente nesta mesma base biológica se manifesta os sentimentos (DAMÁSIO, 2012, p. 216).

É como se estivéssemos possuídos por uma paixão pela razão, um impulso que tem origem no cerne do cérebro, atravessa outros níveis do sistema nervoso e, finalmente, emerge quer como sentimento quer como predisposições não conscientes que orientam a tomada de decisão. A razão, da prática à teórica, baseia-se provavelmente nesse impulso natural por meio de um processo que faz lembrar o domínio de uma técnica ou de uma arte. Retira-me o impulso, e não mais é possível alcançar essa perícia. Mas o fato de se possuir esse impulso não faz de nós, automaticamente, peritos (DAMÁSIO, 2012, p. 216).

O autor deixa claro que "Conhecer a relevâncias das emoções nos processo de raciocínio não significa que a razão seja menos importante do que as emoções, que deve ser relegada a segundo plano ou deva ser menos cultivada. [...]." (DAMÁSIO, 2012, p. 2016).

Não se trata de um menosprezo a razão, mas sim a descoberta de que ela não se manifesta sem que receba carga dos sentimentos, pois não se está no mundo sem que se tenha experiências e estas experiências deixam marcas que afloram emoções. É preciso pensar sobre isso e sair das amarras de que um juiz julga com base única e exclusivamente na razão.

Além dos conhecimentos sólidos sobre as leis e sobre o mundo de forma geral, ele precisa ser capaz de tentar dominar as suas emoções. Questiona-se se é possível decidir, ao mesmo tempo, com justiça sem considerar os sentimentos o que os estudos mostram que não é possível dissociar razão da emoção.

Os juízes não são neutros e o seu julgamento convoca-envolve-produz emoções (racionais e irracionais). As emoções racionais não devem ser suprimidas, elas devem ser assumidas em sua inevitabilidade e importância no âmbito do processo racional de decisão e no âmbito da decisão judicial. (SILVESTRE, 2011, p. 285-307)

Não há neutralidade como apontam o estudos ainda mais com a massificação da informação sensacionalista, pois não há juiz fora do mundo, blindado para influências exógenas a sua jurisdição.

Revista de Direito Penal, Processo Penal e Constituição | e-ISSN: 2526-0200 | Goiânia | v. 5 | n. 1 | p. 22 - 41 | Jan/Jun. 2019. 
No próximo capítulo tratar-se-á de casos polêmicos na Comarca de Canoas, no Estado do Rio Grande do Sul em que fica nítida observação do tempo de cada processo e a importância dada pela mídia, demonstrando assim um nexo de causalidade vinculando interesses e celeridade processual.

\subsubsection{Estudo de caso - Comarca de Canoas}

O capítulo vai tratar de demonstrar casos polêmicos na referida Comarca e apresentará o nexo de causalidade entre interesses e celeridade processual.

\section{Caso 1 - Tentativa de homicídio, cárcere privado e outros delitos}

O caso, que ficou conhecido na imprensa como o maior cárcere privado da história do Rio Grande Sul, ${ }^{* * * * * *}$ ganhou ampla cobertura dos veículos de comunicação. O acusado foi preso em flagrante em 17 de fevereiro 2010, após manter por 72 horas a ex-companheira e os filhos em cárcere privado, na residência da família, em Canoas,tendo a prisão preventiva decretada dois dias depois. O pedido de revogação da prisão foi indeferido pelo juiz.

A denúncia foi recebida em 8 de março de 2010, dando início ao processo. A primeira e a segunda audiência ocorreram em 14 e 25 de maio do mesmo ano, respectivamente. Seguiu assim o trâmite normal. Encerradas todas as diligências, o processo já estava concluso para sentença em 12 de janeiro 2011, sendo a defesa notificada por nota de expediente da sentença de pronúncia em 03 de fevereiro. A defesa recorreu, mas o Tribunal de Justiça manteve a sentença de pronúncia e, com o retorno dos autos, foi designado o julgamento no Plenário do Júri para 02 de abril de 2012. A pedido do MP, com a concordância da defesa, foi suspenso o processo para perícia no IPF.

O réu foi julgado e condenado, parcialmente, em 22 de abril de 2013. No dia seguinte à condenação a defesa tomou conhecimento de que um dos jurados não estava convocado (edital) e não havia cumprido o tempo de espera para atuar no julgamento. Alegando nulidade absoluta, a defesa solicitou novo julgamento. Mesmo com a concordância do promotor da Comarca o Tribunal de Justiça julgou o pedido improcedente. No novo recurso, dessa vez

\footnotetext{
${ }^{* * * * * *}$ BRASIL. Tribunal de Justiça do Estado do Rio Grande do Sul - TJRS. Processo no 008/2010.00011235. Disponível em: <www.tjrs.jus.br/consulta > Disponível em: 5 fev. 2019.
} 
para a instância superior, em Brasília, também julgou improcedente o pedido, tendo o processo transitado em julgado na data de 18de dezembro de 2015.

\section{Caso 2 - Homicídio}

Trata-se de crime ocorrido em 18 de setembro de 2006, com autoria identificada desde o início. ${ }^{\dagger \dagger \dagger \dagger}$ Considerando que no momento do homicídio a polícia já tinha a informação dos autores do delito, entre a investigação e a denúncia foram 6 (seis) meses e 20 (vinte) dias. A denúncia do Ministério Público ocorreu em 08 de maio de 2007 gerando o primeiro volume do processo, que passou por uma cisão.

Em 30 de abril de 2008, o juiz, em razão de substituição, determinou que o processo aguardasse por 15 (quinze) dias no cartório. Com o retorno do juiz titular, o despacho foi dado em 28 de julho, ou seja, 3 (três) meses depois, marcando audiência somente para 02 de dezembro. Alguns dias antes, o promotor requereu o adiamento alegando outro compromisso. Com isso, o juiz determinou que o processo ficasse mais 45 (quarenta e cinco) dias no cartório.

Um novo despacho ocorreu apenas março de 2009, quando uma outra audiência foi marcada para 15 de maio. Em abril, o juiz remarcou a audiência para setembro. Houve, porém, um novo cancelamento em junho, em virtude de férias. Depois de alguns meses, assumiu o processo uma nova juíza ocorrendo finalmente a audiência em 26 de agosto de 2010. Após outras trocas de julgadores e de sucessivas remarcações, devido a situações como a falta de escolta e a não intimação de testemunhas, a próxima audiência pode ser realizada apenas em maio de 2014. A etapa da instrução foi encerrada em setembro daquele ano.

Passado o período de apresentação de alegações finais do MP e da defesa, a sentença de pronúncia foi proferida em março de 2015. Os recursos impetrados pela defesa foram negados pelo juiz e Tribunal de Justiça.

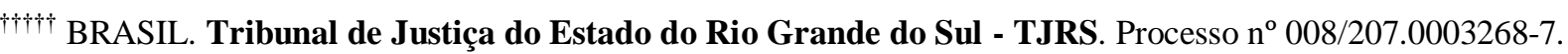
Disponível em: <www.tjrs.jus.br/consulta > Disponível em: 5 fev. 2019.
}

Revista de Direito Penal, Processo Penal e Constituição | e-ISSN: 2526-0200 | Goiânia | v. 5 | n. 1 | p. 22 - 41 | Jan/Jun. 2019. 
Depois de o júri ser marcado e cancelado quatro vezes o julgamento finalmente aconteceu em 20 de abril de 2018 - passados quase 12 (doze) anos do crime e 11 (onze) anos do início do processo - o réu foi parcialmente condenado, tendo recorrido da decisão. $\mathrm{O}$ recurso foi negado pelo Tribunal de Justiça em 25 de outubro.

O réu nunca cumpriu a sentença, pois foi assassinado dias antes da decisão do recurso no Tribunal de Justiça. Esse foi o desfecho de um processo que trocou nove vezes de juiz.

O que se verifica, dos dois casos, é que tramitaram de forma diferente tendo em vista o interesse e divulgação dado pela mídia no primeiro caso do cárcere privado. Já no segundo caso ocorreu a longa espera de quase 12 (doze) anos.

\section{Conclusão}

O artigo propôs o estudo de caso e a abordagem de temas polêmicos como a razoável duração do processo, bem como se há interferência da mídia ocasionando maior celeridade na apuração dos casos criminais.

No que se refere ao processo penal e ao prazo razoável de duração verifica-se que parte da doutrina sugere o uso de exemplos de países vizinhos, como, por exemplo, aquele apresentado como prazo razoável duração do processo no Paraguai, sugestão que sempre recebe críticas e desculpas, como, por exemplo, aquela de que no Brasil não funcionaria a proposta por que ele tem extensão territorial. Ao que parece tem o intuito a crítica de não fazer absolutamente nada, se quer tentar, deixar as coisas como estão, pois a prisão e o processo são forma de punição.

No que se refere a análise dos processos da Comarca de Canoas, no Estado do rio Grande do Sul, reforça a compreensão de que os processos que possuem maior apelo popular e ganham repercussão na imprensa tendem a tramitar de forma mais célere. Já aqueles que não mobilizam a opinião pública levam anos para serem resolvidos, alguns chegando a correr risco de prescrição. Um processo que leva anos para ser resolvido já possui um rótulo de passado e, muitas vezes, deixa de ser prioridade, punindo muitas vezes aquele acusado por um tempo de prisão preventiva sem definição de tempo, ou pelo olhar da vítima ou de seus familiares que esperam a solução do caso penal com a responsabilização daquele que fora acusado pelo cometimento do crime que sofreu.

Revista de Direito Penal, Processo Penal e Constituição | e-ISSN: 2526-0200 | Goiânia | v. 5 |

n. 1 | p. 22 - 41 | Jan/Jun. 2019. 
Fica mais claro que não está a par do mundo o juiz que julga os casos e ao que indica não consegue dissociar a emoção da razão, sofrendo também as influências apontadas pela pesquisa, ou seja, não há neutralidade, pois o julgador está no mundo.

\section{Referências}

ANGRIMANI Sobrinho, Danilo. Espreme que sai sangue: um estudo do sensacionalismo na imprensa. São Paulo: Summus, 1995.

BRASIL. Constituição (1988). Constituição da República Federativa do Brasil. Brasília, DF: Senado Federal, 1988.

BRASIL. Conselho Nacional de Justiça. Justiça em Números 2018. Brasília, 2018.Disponível em<http://www.cnj.jus.br/files/conteudo/arquivo/2018/08/44b7368ec6f888b383f6c3de40c32 167.pdf>. Acesso em: 04 fev.2018.

BRASIL. Tribunal de Justiça do Estado do Rio Grande do Sul - TJRS. Processo no 008/2010.0001123-5. Disponível em: <www.tjrs.jus.br/consulta > Disponível em: 5 fev. 2019.

BRASIL. Tribunal de Justiça do Estado do Rio Grande do Sul - TJRS. Processo $\mathbf{n}^{\circ}$ 008/207.0003268-7. Disponível em: <www.tjrs.jus.br/consulta > Disponível em: 5 fev. 2019.

BARBOSA, Rui. A imprensa e o dever da verdade. São Paulo: Com-Arte; Editora da Universidade de São Paulo, 1990 (Clássicos do Jornalismo Brasileiro; 2).

CASTILHOS, Tiago Oliveira de. Prisão cautelar e prazo razoável. Curitiba: Juruá, 2013.

Comissão Interamericana de Direitos Humanos. Disponível em: < https://www.cidh.oas.org/basicos/portugues/d.Convencao_Americana_Ratif..htm > Acesso em: 10 fev. 2019.

DAMÁSIO, António R. O erro de Descarte: emoções, razão e o cérebro humano; tradução Dora Vicente, Georgina Segurado. 3 ed. São Paulo: Companhia das Letras. 2012.

D'ANCONA, Matthew. Pós-verdade; tradução Carlos Szlak. 1 ed. Baueri: Faro. 2018.

DESCARTES, René, 1596-1650. Discurso do Método; tradução de Paulo Neves. Porto Alegre: L\&PM. 2009.

DORNELES, Carlos. Bar bodega: um crime de imprensa. São Paulo: Globo, 2007.

Revista de Direito Penal, Processo Penal e Constituição | e-ISSN: 2526-0200 | Goiânia | v. 5 |

n. 1 | p. 22 - 41 | Jan/Jun. 2019. 
Código de Ética dos Jornalistas Brasileiros. Disponível em: < https://fenaj.org.br/wpcontent/uploads/2014/06/04-codigo_de_etica_dos_jornalistas_brasileiros.pdf>. Acesso em: 06 fev.2019.

GAUER. Ruth Maria Chittó. Falar em tempo, viver o tempo! In: GAUER. Ruth Maria Chittó (org.). Tempo e historicidades. Porto Alegre: EDIPUCRS. 2016.

HAWKING, Stephen. O universo numa casca de noz. Tradução de Ivo Kovytewski; revisão técnica de Augusto Danieli. 5. ed. São Paulo: Arx. 2002.

Uma breve história do tempo; ilustração Ron Miller; tradução Cássio de Arantes Leite. 1 ed. Rio de Janeiro: Intrínseca. 2015.

LOPES JR. Introdução crítica ao processo penal: fundamentos da instrumentalidade constitucional. 4 ed. rev. atual e ampl. Rio de Janeiro: Lumen Juris. 2006.

LOPES JR, Aury; BADARÓ, Gustavo Henrique. Direito ao processo penal no prazo razoável. $2^{\text {a }}$. ed. Rio de Janeiro: Lumen Juris, 2009.

MESSUTI, Ana. O tempo como pena. São Paulo: Editora dos Tribunais, 2003.

MORETTO, Rodrigo. Crítica interdisciplinar da pena de prisão: controle do espaço na sociedade do tempo. Rio de Janeiro: Lumen Juris. 2005.

POZZEBON, Fabrício Dreyer de Ávila. Reflexos da crise do conhecimento moderno na jurisdição: fundamentos da motivação compartilhada no processo penal. 2005. Tese (Doutorado em Direito) - Faculdade de Direito, Pontifícia Universidade Católica do Rio Grande do Sul, Porto Alegre, 2005.

RAMONET, Ignacio. A tirania da comunicação. 5a . Ed. Petrópolis/RJ: Vozes, 2010.

THUMS, Gilberto. Sistemas processuais penais: tempo, tecnologia, dromologia, garantismo. Rio de Janeiro: Lumen Juris. 2006.

VIRILIO, Paul. A Inércia polar. Tradução de Ana Luísa Faria. Lisboa: Dom Quixote, 1993.

Revista de Direito Penal, Processo Penal e Constituição | e-ISSN: 2526-0200 | Goiânia | v. 5 |

n. 1 | p. 22 - 41 | Jan/Jun. 2019. 